\title{
Differences between anthropometric indicators and the impact force of taekwondo kicks performed with the dominant and non-dominant limb
}

\author{
Michał Górski, Joanna Orysiak \\ Institute of Sport - National Research Institute, Warsaw, Poland
}

\section{Summary}

Study aim: Taekwondo is known for its very dynamic sports fighting, in which the athletes perform strikes mainly with their lower limbs. The aim of the study was to compare the differences between the impact force of strikes performed with the dominant and non-dominant limbs and its correlation with anthropometric indicators.

Material and methods: Six elite Olympic taekwondo players took part in the research $(20.0 \pm 3.2$ years, $185.0 \pm 8.5 \mathrm{~cm}$, $75.3 \pm 10.9 \mathrm{~kg}$ ). Body composition including body mass, percent of body fat (FATP), fat mass (FATM), fat-free mass (FFM) and muscle mass $(\mathrm{MM})$ was determined by bioelectric impedance analysis. Maximal strike impact force $\left(\mathrm{F}_{\max }\right)$ and $\mathrm{F}_{\max }$ relative to FFM ( $\left.\mathrm{F}_{\max } \cdot \mathrm{FFM}^{-1}\right)$ of roundhouse kick (dollyo chagi) and side kick (yop chagi) were measured using a dynamometric punching bag with an embedded accelerometer.

Results: We found significant differences between the dominant limb (DL) and non-dominant limb (NL) in anthropometric analysis: FATP was $10.52 \pm 5.38 \%$ and $11.32 \pm 4.83 \%$, FFM was $11.87 \pm 0.97 \mathrm{~kg}$ and $11.43 \pm 1.09 \mathrm{~kg}, \mathrm{MM}$ was $11.25 \pm 0.92 \mathrm{~kg}$ and $10.82 \pm 1.02 \mathrm{~kg}$ for DL and NL respectively. In dollyo chagi $\mathrm{F}_{\max }$ and $\mathrm{F}_{\max } \cdot \mathrm{FFM}^{-1}$ were higher for DL than NL and were $2733 \pm 748 \mathrm{~N}$ and $2206 \pm 778 \mathrm{~N}, 41.34 \pm 8.16 \mathrm{~N} \cdot \mathrm{kg}^{-1}$ and $33.29 \pm 9.02 \mathrm{~N} \cdot \mathrm{kg}^{-1}$ respectively. Yop chagi has a lower impact force compared to dollyo chagi. $\mathrm{F}_{\max }$ and $\mathrm{F}_{\max } \cdot \mathrm{FFM}^{-1}$ for $\mathrm{DL}$ and $\mathrm{NL}$ were $1763 \pm 303 \mathrm{~N}$ and $1779 \pm 372 \mathrm{~N}, 26.76 \pm 3.07$ $\mathrm{N} \cdot \mathrm{kg}^{-1}$ and $26.9 \pm 3.57 \mathrm{~N} \cdot \mathrm{kg}^{-1}$ respectively. We found a significant correlation between $\mathrm{F}_{\max }$ in yop chagi and $\mathrm{FFM}(\mathrm{R}=0.83$, $\mathrm{p}<0.05)$.

Conclusions: Athletes should fight using a stance where the dominant limb is moved further away from the target in order to strike with maximum force.

Key words: Martial arts - Impact force - Asymmetry - Anthropometry - Biomechanics

\section{Introduction}

Olympic taekwondo is known for its very dynamic sports fighting, in which the athletes perform strikes mainly with their lower limbs. It is believed that one of the most important factors that may have an impact on the course of the fight is the force of the strike $[10,16]$. To date, the evaluation of the impact force in the laboratory environment has been performed using various methods $[5,7,9-11,15,17,18]$. With the multitude and variety of methods used, the impact force is recorded within a very wide range of results. Furthermore, the impact force may depend on a number of different factors, such as the sports skill level [9], the athlete's ability to use total body mass [16], the distance from the target [7], or the attack technique [17]. It was found that the impact force of the roundhouse kick (dollyo chagi) with the rear leg is significantly higher than the front leg $[3,5]$ because the rear leg moves in this case at a higher speed [14]. On the other hand, the results of the force of the strikes performed with dominant and non-dominant limbs are inconsistent $[10,16]$. It is worth noting that the absolute impact force of strikes may differ between athletes with different body mass [16]. Therefore the participants of taekwondo competitions are divided into a number of weight categories [8]. Consequently, body mass control is an integral part of the training process and is usually achieved by maintaining a low level of body fat [2]. An extremely important aspect of preparation for competitions is to maintain an optimal ratio of body fat to muscle tissue. Too rapid weight reduction can have a negative impact on the ability to cope with the demands of sports fighting [6]. The aim of the study was to compare the differences between the impact force of kicks performed with the dominant and non-dominant limbs and its correlation with anthropometric indicators. 


\section{Material and methods}

\section{Participants}

Six athletes took part in the research (Table 1). All the athletes were members of the Polish national Olympic taekwondo team and had high skills confirmed by a master's rank (black belt). All the participants were medalists of the national Olympic taekwondo championships and declared the right leg as a dominant limb. None of them reported any injury of the lower limb joints for six months prior to the study. Ethical approval for this study was provided by the Local Ethical Committee at the Institute of Sport - National Research Institute, Warsaw, Poland, no. KEBN-16-20-MG. Written informed consent was obtained from the participants. The study was conducted in accordance with the Declaration of Helsinki.

\section{Anthropometric measurements}

Body height was assessed using a Siber Hegner anthropometer (Zurich, Switzerland) with accuracy of $0.1 \mathrm{~cm}$. Body composition, including body mass (BM), percent of body fat (FATP), fat mass (FATM), fat-free mass (FFM) and muscle mass (MM), was determined by bioelectric impedance analysis using a Tanita MC 180MA instrument (Japan).

\section{Impact force measurement}

Strike force was measured using a dynamometric punching bag with an embedded accelerometer. It is a long, cylinder-shaped bag $(\mathrm{L}=1.8 \mathrm{~m} ; \mathrm{D}=0.42 \mathrm{~m}$; mass $=41 \mathrm{~kg}$ ) consisting of a stiff inner cylinder and an outer layer to absorb the shock (for details see [3, 5]). For measurement purposes, two tri-axial accelerometers with triaxial gyroscope modules mounted on the edge surfaces of the punching bag's inner cylinder base were applied. Computation of the impact force of the strike was calculated using BTS6v0 software ("JBA" Zb. Staniak, Poland). The data were collected with a frequency of $500 \mathrm{~Hz}$ and filtered using a Butterworth digital low-pass filter with cut-off frequency of $50 \mathrm{~Hz}$. Two signaling diodes were attached to the bag. The measurement error of acceleration is less than $1 \%$. The accelerometer-based method results show that the mean relative error of force calculation is $3 \%$.

The two attack techniques most commonly used in sports fighting were analyzed: roundhouse kick (dollyo chagi), performed with the rear leg, i.e. that further from the target, and side kick (yop chagi), performed with the front leg, i.e. that closer to the target, without making any additional step forward. The task of the participant was to kick a punching bag with as much force as possible upon a light signal, which was a flash of a light emitting diode $[1,7]$. The time between the LED flashes was random.

The time interval between each LED flash was calculated using the following formula:

Interval $[\mathrm{s}]=$ constant interval $[\mathrm{s}] \pm$ random interval $[\mathrm{s}]$

Constant time interval was set to 5 , and random time interval was a random number between 0 and 1 .

All kicks were performed from the fighting stance. Each participant's preferred target distance was used as the execution distance [12]. No bounce was allowed during preparation and there was no audio instruction or command [13]. Five strikes were recorded for each technique. The techniques with the highest value of the impact force were chosen for the analysis.

\section{Statistical analysis}

Distribution of all variables investigated was evaluated by the Shapiro-Wilk test. All variables were normally distributed. A repeated measures analysis of variance was used to compare the study results between the dollyo chagi and yop chagi techniques. The significance of differences between means was evaluated post hoc with the Scheffe test. Differences of anthropometric indicators were evaluated with the dependent sample t-test. Relationships between all variables were assessed by calculating Pearson's linear correlation coefficients. For the statistical analyses, the value of $\alpha=0.05$ was considered as significant. All computations were performed with STATISTICA software (v. 12.0, StatSoft, USA).

\section{Results}

Table 1 contains the results of anthropometric measurements of the athletes. Table 2 contains anthropometric indices characterizing only the lower limbs. Fat percentage in the right lower limb was significantly lower than

Table 1. Mean ( \pm standard deviation) of measured anthropometric indicators

\begin{tabular}{cccccccc}
\hline Age $[$ years $]$ & BH $[\mathrm{cm}]$ & BM $[\mathrm{kg}]$ & BMI $\left[\mathrm{kg} \cdot \mathrm{m}^{-2}\right]$ & FATP $[\%]$ & FATM $[\mathrm{kg}]$ & MM $[\mathrm{kg}]$ & FFM $[\mathrm{kg}]$ \\
\hline $20.0 \pm 3.2$ & $185 \pm 8.5$ & $75.3 \pm 10.9$ & $21.9 \pm 2.2$ & $12.3 \pm 3.3$ & $9.5 \pm 3.7$ & $62.5 \pm 7.4$ & $65.8 \pm 7.8$ \\
\hline
\end{tabular}

BH - body height, BM - body mass, FATP - percent of body fat, FATM - fat mass, FFM - fat-free mass, MM - muscle mass, BMI - body mass index. 
Table 2. Anthropometric indicators (mean \pm standard deviation) characterizing lower limbs

\begin{tabular}{lcccc}
\hline & DL & NL & t & p \\
\hline FATP [\%] & $10.52 \pm 5.38$ & $11.32 \pm 4.83$ & -2.72 & $<0.05$ \\
FATM [kg] & $1.45 \pm 0.88$ & $1.52 \pm 0.78$ & -1.51 & $\mathrm{~ns}$ \\
FFM [kg] & $11.87 \pm 0.97$ & $11.43 \pm 1.09$ & 6.92 & $<0.01$ \\
SMM [kg] & $11.25 \pm 0.92$ & $10.82 \pm 1.02$ & 7.21 & $<0.001$ \\
\hline
\end{tabular}

FATP - percent of body fat, FATM - fat mass, FFM - fat-free mass, SMM - skeletal muscle mass, DL - dominant limb, NL - nondominant limb, ns - statistically non-significant.

in the left $(\mathrm{p}<0.05)$. The right limb was characterized by significantly greater lean body mass $(\mathrm{p}<0.01)$ and skeletal muscle mass $(\mathrm{p}<0.01)$.

Table 3 includes the measured values of the maximum impact force and the relative impact force of the kicks. The values of the maximum impact force of dollyo chagi were significantly higher than those of yop chagi in the case of both the dominant and non-dominant limbs $(\mathrm{p}<0.05)$.
The impact force of the dollyo chagi kick performed with the dominant limb was significantly higher than that performed with the non-dominant limb $(p<0.05)$.

Table 4 contains Pearson's correlation coefficients between measured variables. A statistically significant correlation was found between the force of yop chagi performed with the non-dominant limb and lean body mass of the dominant limb $(\mathrm{R}=0.84 ; \mathrm{p}<0.05)$.

Table 3. Maximum impact force (mean \pm standard deviation) and relative impact force of taekwondo strikes

\begin{tabular}{|c|c|c|c|c|c|c|c|c|}
\hline & \multicolumn{2}{|c|}{ Dollyo chagi } & \multicolumn{2}{|c|}{ Yop chagi } & \multirow{2}{*}{ Effect } & \multirow{2}{*}{$\mathrm{F}_{1,5}$} & \multirow{2}{*}{$\mathrm{p}$} & \multirow{2}{*}{$\eta^{2}$} \\
\hline & $\mathrm{DL}$ & NL & $\mathrm{DL}$ & $\mathrm{NL}$ & & & & \\
\hline \multirow{3}{*}{$\mathrm{F}_{\max }[\mathrm{N}]$} & \multirow{3}{*}{$2733 \pm 748$} & \multirow{3}{*}{$2206 \pm 778$} & \multirow{3}{*}{$1763 \pm 303$} & \multirow{3}{*}{$1779 \pm 372$} & side & 8.16 & $<0.05$ & 0.62 \\
\hline & & & & & technique & 20.44 & $<0.01$ & 0.80 \\
\hline & & & & & side $\mathrm{x}$ technique & 16.87 & $<0.01$ & 0.77 \\
\hline \multirow{3}{*}{$\begin{array}{l}\mathrm{F}_{\max } \cdot \mathrm{FFM}^{-1} \\
{\left[\mathrm{~N} \cdot \mathrm{kg}^{-1}\right]}\end{array}$} & \multirow{3}{*}{$41.34 \pm 8.16$} & \multirow{3}{*}{$33.29 \pm 9.02$} & \multirow{3}{*}{$26.76 \pm 3.07$} & \multirow{3}{*}{$26.9 \pm 3.57$} & side & 18.65 & $<0.01$ & 0.79 \\
\hline & & & & & technique & 10.28 & $<0.05$ & 0.67 \\
\hline & & & & & side $\mathrm{x}$ technique & 17.54 & $<0.01$ & 0.78 \\
\hline
\end{tabular}

$\mathrm{DL}$ - dominant limb, NL - non-dominant limb.

Table 4. Pearson's linear correlation coefficients between selected anthropological indicators and maximum impact force of taekwondo strikes

\begin{tabular}{|c|c|c|c|c|c|c|c|c|c|c|c|c|}
\hline & & $\mathrm{BH}$ & $\mathrm{BM}$ & FATP & FATM & FFM & $\begin{array}{l}\text { DL- } \\
\text { FATP }\end{array}$ & $\begin{array}{c}\text { DL- } \\
\text { FATM }\end{array}$ & $\begin{array}{l}\text { DL- } \\
\text { FFM }\end{array}$ & $\begin{array}{l}\text { NL- } \\
\text { FATP }\end{array}$ & $\begin{array}{c}\text { NL- } \\
\text { FATM }\end{array}$ & $\begin{array}{l}\text { NL- } \\
\text { FFM }\end{array}$ \\
\hline \multirow{4}{*}{ DL } & $\mathrm{F}_{\text {max }}$ dollyo & -0.15 & 0.49 & -0.10 & 0.07 & 0.65 & -0.21 & -0.15 & 0.71 & -0.29 & -0.19 & 0.66 \\
\hline & $\mathrm{F}_{\max } \mathrm{yop}$ & 0.27 & 0.72 & 0.35 & 0.46 & 0.79 & 0.23 & 0.27 & 0.79 & 0.18 & 0.25 & 0.77 \\
\hline & $\mathrm{F}_{\text {max }}$ dollyo $\cdot \mathrm{FFM}^{-1}$ & -0.53 & 0.06 & -0.49 & -0.35 & 0.25 & -0.52 & -0.49 & 0.33 & -0.57 & -0.53 & 0.26 \\
\hline & $\mathrm{F}_{\max } \mathrm{yop} \cdot \mathrm{FFM}^{-1}$ & -0.20 & 0.08 & -0.08 & -0.06 & 0.15 & -0.05 & -0.08 & 0.15 & -0.03 & -0.06 & 0.12 \\
\hline \multirow{4}{*}{ NL } & $\mathrm{F}_{\max }$ dollyo & -0.19 & 0.46 & -0.03 & 0.11 & 0.58 & -0.07 & -0.03 & 0.64 & -0.13 & -0.06 & 0.60 \\
\hline & $\mathrm{F}_{\max } \mathrm{yop}$ & 0.21 & 0.73 & 0.27 & 0.41 & $0.83^{*}$ & 0.15 & 0.19 & $0.84^{*}$ & 0.10 & 0.17 & 0.81 \\
\hline & $\mathrm{F}_{\text {max }}$ dollyo $\cdot \mathrm{FFM}^{-1}$ & -0.47 & 0.14 & -0.28 & -0.18 & 0.28 & -0.24 & -0.24 & 0.34 & -0.28 & -0.26 & 0.29 \\
\hline & $\mathrm{F}_{\max } \mathrm{yop} \cdot \mathrm{FFM}^{-1}$ & -0.19 & 0.28 & -0.08 & 0.00 & 0.40 & -0.07 & -0.09 & 0.41 & -0.09 & -0.09 & 0.37 \\
\hline
\end{tabular}

Dollyo - dollyo chagi, yop - yop chagi, BH - body height, BM - body mass, FATP - percent of body fat, FATM - fat mass, FFM - fat-free mass, $\mathrm{DL}$ - dominant limb, NL - non-dominant limb * - statistically significant correlation $\mathrm{p}<0.05$. 


\section{Discussion}

The aim of the study was to compare the differences between the impact force of kicks performed with the dominant and non-dominant limbs and its correlation with anthropometric indicators. In our study, the values of the maximum impact force of dollyo chagi were higher than those of yop chagi in both dominant and non-dominant limbs. In the case of the dominant limb, the impact force of the dollyo chagi kick was significantly higher compared to the non-dominant limb $(\mathrm{p}<0.05)$. The impact force of the yop chagi kick did not differ between the dominant and non-dominant limbs. Furthermore, in the dominant limb, the percentage of body fat was lower than in the non-dominant limb, whereas the muscle mass was higher.

One of the most important parameters in combat sports which have a direct impact on the effectiveness of the fight is the impact force of strikes. Differences in the impact force of taekwondo kicks performed by the dominant and non-dominant limbs have been evaluated in several studies. In Polish elite athletes, the impact force of yop chagi with the dominant limb was higher compared to the kick performed with the non-dominant limb (9015 \pm 2382 [N] and $8294 \pm 2308$ [N], respectively) [16]. The findings published by Pędzich et al. [16] and our results are contradictory to those presented by Falco et al. [10]. The impact force of dollyo chagi performed with the non-dominant limb by Spanish athletes was between 867 and 1024 [N] , and did not differ from the values recorded for the dominant limb, which ranged between 961 and 1318 [N]. The results depended on the distance from which the kick was performed. In our opinion, the occurrence or absence of differences in the impact force of the strikes between the dominant and non-dominant limbs may result from the technical skills, experience or sports skill level of the taekwondo competitors [7, 10]. Furthermore, how a strike is performed may be associated with the dynamically changing sports regulations. Changes in rules could affect some technical and tactical aspects of fighting. The lack of statistically significant differences in some studies could also be caused due to different ways of presentation of the results. Some authors normalized force values depending on body mass, while others did not [7]. Differences in measurements may also result from different methods of assessing the impact force, e.g. a bag filled with water [17], a punching bag with an embedded accelerometers [5], force plate [16] or a system based on piezoelectric pressure sensors placed in a dummy [10]. Due to different techniques of measuring the impact force, there is a problem with the interpretation of the results and their comparisons between each other. It seems that the measurement results are substantially affected by the design of the measurement system and its inertia.
To the best of our knowledge, few studies have described differences in the measured impact force of both yop chagi and dollyo chagi techniques of Olympic taekwondo players [17]. Buśko et al. [5] and Buśko and Nikoladis [3] analyzed the differences between the force of dollyo chagi performed with the front and rear leg. In these studies, the impact force of the roundhouse kicks was significantly lower when the kick was performed with the leg closer to the target than when it was performed with the rear leg (further from the target). The analysis of differences between kicks performed in two variants - with the front and rear leg - in studies by Buśko concerned only dollyo chagi kicks, whereas in our study, two kicks were compared: yop chagi with the front leg and dollyo chagi, performed with the rear leg. This makes it impossible to directly compare the results of our research with the findings of the above-mentioned authors. It can be observed, however, that the kicks with the limb positioned further away from the target were significantly stronger. Differences in the impact force of the kicks performed with the front and rear leg may result from the distance the foot of the kicking leg has to cover. Greater distance allows the athlete to accelerate the limb for a longer time before the impact [14]. Furthermore, the impact force is generated in a different way in the case of the attack techniques tested in our study. The impact force of dollyo chagi technique is produced mainly through the skillful use of energy transfer, in accordance with the principle of the kinetic chain $[9,10]$. In the case of the side kick (yop chagi), which can be described as a dynamic push, the force of the blow comes mainly from the athlete's skilful use of his or her own body mass [16]. When performing the kick, the athlete first lifts the front leg, bending it at the knee joint at the same time. Next, they bounce towards the opponent with their rear leg in order to extend the knee and hit the target in the final phase of the kick. The attack technique presented in this way requires strong muscles of the support leg, responsible for a dynamic rebound from the ground. In our study, we found a correlation between the lean body mass of the dominant limb and the force of yop chagi performed with the non-dominant limb $(\mathrm{R}=0.84$, $\mathrm{p}<0.05)$. There are different opinions in the literature on the relationship between body mass and the impact force of taekwondo kicks. Pędzich et al. [16] reported a correlation between the maximum force of yop chagi and body mass of the athletes. Estevan et al. [7] found a correlation between the impact force of dollyo chagi kicks and body mass of athletes only for those with shorter training experience. In our study, there were no statistically significant correlations between the impact force of the kick studied and body mass of athletes. However, a correlation was observed between the impact force of yop chagi and lean body mass $(\mathrm{R}=0.83, \mathrm{p}<0.05)$. The lack of statistically significant correlations may result from the small number 
of study participants, which is the greatest limitation of our study.

In conclusion, dollyo chagi is a kick that allows a higher maximum impact force to be generated for the dominant and non-dominant limb, compared to yop chagi. The difference in the impact force between the kicks performed with the dominant and non-dominant limbs occurs only in the case of a roundhouse kick performed with the rear leg. There is a significant relationship between the impact force of taekwondo kicks and lean body mass of the athlete. We recommend athletes to fight using a stance where the dominant limb is moved further away from the target in order to strike with maximum force.

Conflict of interest: Authors state no conflict of interest.

\section{References}

1. Balkó S., Rous M., Balkó I., Hnízdil J., Borysiuk Z. (2017) Influence of a 9-week training intervention on the reaction time of fencers aged 15 to 18 years. Phys. Activ. Rev., 5: 146-154.

2. Bridge C.A., da Silva Santos J.F., Chaabene H., Pieter W., Franchini E. (2014) Physical and physiological profiles of taekwondo athletes. Sports Med., 44(6): 713-733.

3. Buśko K., Nikolaidis P.T. (2018) Biomechanical characteristics of Taekwondo athletes: kicks and punches vs. laboratory tests. Biomed. Hum. Kinet., 10(1): 81-88.

4. Buśko K., Staniak Z., Łach P., Mazur-Różycka J., Michalski R., Górski, M. (2014) Comparison of two boxing training simulators. Biomed. Hum. Kinet., 6(1): 135-141.

5. Buśko K., Staniak Z., Szark-Eckardt M., Nikolaidis P.T., Mazur-Różycka J., Łach P., Michalski R., Gajewski J., Górski M. (2016) Measuring the force of punches and kicks among combat sport athletes using a modified punching bag with an embedded accelerometer. Acta Bioeng. Biomech., 18(1): 47-54.

6. de Sousa Fortes L., de Vasconcelos G.C., de Vasconcelos Costa B.D., Paes P.P., Franchini E. (2017) Effect of 10\% weight loss on simulated taekwondo match performance: a randomized trial. J. Exerc. Rehabil., 13(6): 659-665. DOI: $10.12965 /$ jer.1735134.567.

7. Estevan I., Falco C. (2013) Mechanical analysis of the roundhouse kick according to height and distance in taekwondo. Biol. Sport, 30(4): 275-279.

8. Estevan I., Jandacka D., Farana R., Falco C. (2012) Kinematic analysis of a roundhouse kick according to the stance position. In: ISBS-Conference Proceedings Archive (Vol. 1, No. 1).
9. Estevan I.A., lvarez O., Falco C., Molina-Garcia J., Castillo I. (2011) Impact force and time analysis influenced by execution distance in a roundhouse kick to the head in Taekwondo. J. Strength Cond. Res., 25(10): 2851-2856.

10. Falco C., Alvarez O., Estevan I., Molina-Garcia J., Mugarra F., Iradi A. (2009) Kinetic and kinematic analysis of the dominant and non-dominant kicking leg in the taekwondo roundhouse kick. In ISBS-Conference Proceedings Archive (Vol. 1, No. 1).

11. Górski M., Lekszycki T., Buśko, K., Mazur-Różycka J. (2014) Modelling and analysis of lower limb joint loads during the Naeryo chagi technique in taekwondo. Biomed. Hum. Kinet, 6(1): 121-127.

12. Kim J.W., Kwon M.S., Yenuga S.S., Kwon Y.H. (2010) The effects of target distance on pivot hip, trunk, pelvis, and kicking leg kinematics in Taekwondo roundhouse kicks. Sports Biomech., 9(2): 98-114.

13. Kim Y.K., Kim Y.H., Im S.J. (2011) Inter-joint coordination in producing kicking velocity of Taekwondo kicks. J. Sports Sci. Med., 10(1): 31-38.

14. Kong P.W., Luk T.C., Hong Y. (2000) Difference between Taekwondo roundhouse kick executed by the front and back leg-a biomechanical study. In: Scientific Proceedings of XVIII International symposium on biomechanics in sports, The Chinese University of Hong Kong. Hong Kong, pp. 277-280.

15. O’Sullivan D., Chung C., Lee K., Kim E., Kang S., Kim T., Shin I. (2009) Measurement and comparison of Taekwondo and Yongmudo turning kick impact force for two target heights. J. Sports Sci. Med., 8(CSSI3): 13-16.

16. Pędzich W., Mastalerz A., Urbanik C. (2006) The comparison of the dynamics of selected leg strokes in taekwondo WTF. Acta Bioeng. Biomech., 8(1): 83-90.

17. Pieter F., Pieter W. (1995) Speed and force in selected taekwondo techniques, Biol. Sport, 12: 257-266.

18. Rocha F., Costa A., Louro H., Conceição A. (2017) The relationship between bandal chagui power with mechanical efficiency in taekwondo athletes. Sci. Int. (Lahore), 29(6): 1231-1236,

\section{Received 22.10.2019 \\ Accepted 09.12.2019}

(C) University of Physical Education, Warsaw, Poland

\section{Acknowledgments}

The study was supported by the Ministry of Science and Higher Education: Institute of Sport No. 104.01. 